\title{
KINETICS OF ECHINOSTOMA CAPRONI (TREMATODA: ECHINOSTOMATIDAE) ANTIGENS IN FECES AND SERUM OF EXPERIMENTALLY INFECTED HAMSTERS AND RATS
}

\author{
Rafael Toledo, Ana Espert, Carla Muñoz-Antoli, Antonio Marcilla, Bernard Fried*, and J. Guillermo Esteban \\ Departamento de Parasitología, Facultad de Farmacia, Universidad de Valencia, Av. Vicente Andrés Estellés s/n, 46100 Burjassot-Valencia, \\ Spain.e-mail: rafael.toledo@uv.es
}

\begin{abstract}
This study reports on the kinetics of antibody production to Echinostoma caproni and the dynamics of antigens in feces and sera in 2 experimental hosts (hamsters and rats) that display different degrees of susceptibility with this echinostome. Echinostoma caproni produced chronic infections in hamsters, whereas rats lost the infection at 49-56 days postinfection (DPI). Hamsters developed higher antibody responses than rats, probably in relation to different intestinal absorptions of worm antigens in each host species. The levels of coproantigens were indicative of the course of infection in each host. Positive coproantigen levels were detected at 1-2 DPI in both hosts, and the values remained positive until the end of the experiment in hamsters; in rats, the coproantigen levels reverted to negative values, coinciding with the loss of infection. High levels of circulating antigens were detected in hamsters from 21 DPI to the end of the study. In contrast, low levels of E. caproni seroantigens were detected in rats only. These observations may reflect the differences in local inflammatory responses induced by E. caproni in each host species.
\end{abstract}

Infections with intestinal trematodes are widespread. Despite the frequency of these infections, the relationships between intestinal trematodes and their final hosts have received little attention. Echinostoma caproni (Trematoda: Echinostomatidae) is an intestinal trematode that does not undergo tissue migration in its definitive host. After infection of the definitive host with E. caproni, the metacercariae excyst in the duodenum, and the juvenile parasites migrate to the posterior third of the small intestine, where they attach to the mucosa by the ventral sucker (Fried and Huffman, 1996).

Echinostoma caproni has a wide range of definitive hosts, although its compatibility differs considerably between rodent species. For instance, hamsters and mice show a high level of compatibility with this echinostome species, whereas rats and jirds display a low level of compatibility (Odaibo et al., 1988, 1989; Christensen et al., 1990; Hansen et al., 1991; Mahler et al., 1995; Toledo, Espert, Muñoz-Antoli et al., 2003). This classification is based mainly on worm survival observed in each host species. In highly compatible hosts E. caproni produces chronic infections, whereas in less-compatible hosts the worms are rapidly expelled. These differences observed in various rodent species indicate that they are highly suitable for elucidating aspects of the host-specific components that determine the course of infections with intestinal trematodes.

In this study, the course of the E. caproni infections in 2 hosts of different compatibilities (golden hamsters and rats) is compared to gain further insight into the host-parasite relationships in intestinal trematode infections. For this purpose, we have evaluated several parameters such as antibody production and the kinetics of antigens in feces of hamsters and rats experimentally infected with $E$. caproni during the first 140 days postinfection (DPI). Moreover, the dynamics of seroantigens is investigated for the first time in echinostome infections. These parameters may be helpful in analyzing the course of E. caproni infections in different host species.

Received 11 November 2003; revised 29 December 2003; accepted 8 January 2004.

* Department of Biology, Lafayette College, Easton, Pennsylvania 18042.

\section{MATERIALS AND METHODS}

\section{Parasite and experimental infections}

The strain of E. caproni has been described previously by Hosier and Fried (1991). Encysted metacercariae of E. caproni were removed from the kidneys and pericardial cavities of experimentally infected Biomphalaria glabrata snails and used to infect golden hamsters (Mesocricetus auratus) and albino rats (Wistar). Each of 10 outbred male golden hamsters, weighing 45-60 g, and 10 rats, weighing 100-130 g, was infected by stomach tube with 100 metacercariae of E. caproni. Five hamsters and 5 rats were left uninfected and used as controls. All the infected animals were maintained under conventional conditions with food and water ad libitum. The parasite egg release was investigated weekly in each of the infected animals as described by Toledo, Espert, Carpena et al. (2003).

\section{Excretory-secretory antigens}

To obtain excretory-secretory (ES) antigens of E. caproni, we followed the methodology described by Toledo, Espert, Muñoz-Antoli et al. (2003). Adult worms were collected from intestines of experimentally infected hamsters and rats 4 wk postinfection with 100 metacercariae of E. caproni. After thoroughly washing with phosphate-buffered saline (PBS, $\mathrm{pH} 7.4$ ), the adult worms were maintained in medium at concentrations of 10 worms $/ \mathrm{ml}$ for $12 \mathrm{hr}$ at $37 \mathrm{C}$ in PBS containing 0.8 $\mathrm{mM}$ phenylmethylsulfonyl fluoride (Sigma, St. Louis, Missouri), $100 \mathrm{U}$ penicillin (Sigma), and $100 \mu \mathrm{g} / \mathrm{ml}$ streptomycin (Sigma). The medium was collected and centrifuged at $15,000 \mathrm{~g}$ for $30 \mathrm{~min}$ at $4 \mathrm{C}$, and the supernatant was collected. The protein content was measured by the BioRad (Hercules, California) protein assay and adjusted to $1 \mathrm{mg} / \mathrm{ml}$ using an ultrafiltration membrane (YM-3, Millipore, Bellerica, Massachusetts). The antigens were stored at $-20 \mathrm{C}$ until use.

\section{Fecal and serum samples}

Fecal samples were collected from each animal just before the experimental infection and daily during the first 7 DPI and then weekly from 7 to 140 DPI. Fecal eluates for the coproantigen detection were prepared as described by Toledo, Espert, Muñoz-Antoli et al. (2003). In brief, $1 \mathrm{~g}$ of fresh feces from individual specimens was suspended in $3 \mathrm{ml}$ of PBS containing $0.05 \%$ Tween 20 (PBST). These suspensions were centrifuged at $900 \mathrm{~g}$ for $30 \mathrm{~min}$. The supernatants were filtered through a $0.2-\mu \mathrm{m}$ pore size membrane (Nalge Nunc, Naperville, Illinois) and collected.

Blood was collected weekly from each infected and control animal by cardiac puncture under anesthesia. After clotting of the blood overnight at $4 \mathrm{C}$, serum was separated from the clot by centrifugation. The supernatant fecal eluates and the serum samples were stored at $-20 \mathrm{C}$ until use. 


\section{Indirect enzyme-linked immunosorbent assay for antibody detection}

To detect specific antibodies against E. caproni ES products, an indirect enzyme-linked immunosorbent assay (ELISA) was carried out as described by Toledo, Espert, Muñoz-Antoli et al. (2003) with some modifications. Polystyrene microtiter plates (Nalge Nunc, Naperville, Illinois) were coated overnight at $4 \mathrm{C}$ with $100 \mu \mathrm{l} / \mathrm{well}$ of a $30 \mu \mathrm{g} / \mathrm{ml}$ solution of ES antigens of E. caproni in $0.1 \mathrm{M}$ carbonate coating buffer, $\mathrm{pH}$ 9.6. The plates were washed 3 times with PBST. Uncoated sites were blocked with 5\% nonfat dry milk in PBST. After incubation for 1 $\mathrm{hr}$ at $37 \mathrm{C}$, the plates were emptied and $100 \mu \mathrm{l}$ of diluted serum (1:400 in PBST) was dispensed into each well. The plates were incubated for $2 \mathrm{hr}$ at room temperature (RT) and then washed 5 times with PBST. One hundred microliters of horseradish peroxidase-conjugated goat anti-hamster or anti-rat IgG (ICN Biomedicals, Aurora, Ohio) diluted 1:3,000 in PBS was added to each well and incubated for $2 \mathrm{hr}$ at RT. The plates were washed as described above, and $100 \mu l$ of the substrate solution $(10 \mu l$ hydrogen peroxide, $30 \%$ [w/v $]+25 \mathrm{ml}$ of $0.1 \mathrm{M}$ citrate buffer, $\mathrm{pH} 5.0,+10 \mathrm{mg} o$-phenylenediamine hydrochloride) was added and incubated in the dark at RT. The enzyme reaction was stopped with $50 \mu 1$ per well of $3 \mathrm{~N} \mathrm{HCl}$. The plates were read at $492 \mathrm{~nm}$ in a BioRad 550 microplate ELISA reader.

\section{Capture ELISA for antigen detection}

The presence of E. caproni ES products in fecal eluates from hamsters and rats was evaluated by a polyclonal antibody-based capture ELISA as described by Toledo, Espert, Muñoz-Antoli et al. (2003). For the determination of ES products in serum samples, the same capture ELISA was used, with some modifications. Before using capture ELISA, the serum samples were treated as described by Van Kerckhoven et al. (1998) to dissociate immune complexes, improving the sensitivity of the test. In brief, the serum samples were heated in a warm water bath at $100 \mathrm{C}$ for $15 \mathrm{~min}$, after which the samples were centrifuged at $10,000 \mathrm{~g}$ for $5 \mathrm{~min}$ and the supernatant was recovered.

The wells of polyestyrene microtiter plates (Nalge Nunc) were sensitized overnight at $4 \mathrm{C}$ with $100 \mu \mathrm{l} /$ well of unlabeled polyclonal antibodies anti-E. caproni ES antigens (Toledo, Espert, Muñoz-Antoli et al., 2003) in a concentration of $30 \mu \mathrm{g} / \mathrm{ml}$ in $0.1 \mathrm{M}$ carbonate buffer, $\mathrm{pH}$ 9.6. They were then washed 3 times with PBST, and unbound sites were blocked with 5\% nonfat dry milk diluted in PBST. After incubation for $1 \mathrm{hr}$ at $37 \mathrm{C}$, the plates were emptied by aspiration. One hundred miroliters of heat-treated serum samples (diluted 1:20 in PBST) was added, and the plates were incubated for $2 \mathrm{hr}$ at RT. Thereafter, they were washed 5 times with PBST. One hundred microliters of biotinylated anti-E. caproni ES antibody (diluted 1:2,000 in PBST) was added to each well and incubated for $2 \mathrm{hr}$ at RT, after which they were washed 5 times as described above. One hundred microliters of labeled streptavidin-peroxidase (Sigma) (diluted 1:5,000 in PBS) was added to each well and incubated for $2 \mathrm{hr}$ at RT. The plates were washed as above, and $100 \mu \mathrm{l}$ of the substrate solution was added and incubated in the dark at RT. The enzyme reaction was stopped with $50 \mu 1 /$ well of $3 \mathrm{~N}$ $\mathrm{HCl}$. The plates were read spectrophotometrically at $492 \mathrm{~nm}$ as described above.

\section{Statistical analysis}

Each ELISA assay was performed in triplicate, and the absorbance readings from wells with the same sample were expressed as the mean $\pm \mathrm{SD}$. The cutoff for each ELISA was defined as the mean of the samples from the control rats $+3 \mathrm{SD}$. The difference between the optical density (OD) values for the infection and control specimens at each point in time was calculated and tested by the use of Student's $t$-test. The correlation between the ES concentration in the spiked samples and the capture ELISA values was analyzed by the Pearson product moment correlation test. $P<0.05$ was considered as significant.

\section{RESULTS}

\section{Development of the infection}

All the hamsters and rats experimentally exposed to 100 metacercariae of E. caproni became infected as determined by egg examination. The duration of the prepatent period was highly uniform. Egg release began 9-10 (9.46 \pm 0.38$)$ DPI in hamsters and 10-12 (11.34 \pm 0.44$)$ DPI in rats. All the hamsters remained positive by egg examination until the end of the experiment, at 140 DPI. In contrast, $7(70 \%)$ of the rats became negative at 49 DPI and the other $3(30 \%)$ were negative at 56 DPI. Worms were recovered at necropsy of the hamsters, at 140 DPI, whereas no worm was recovered from the rats at this point.

\section{Antibody titers}

Antibody titers against antigens of E. caproni in hamsters and rats were investigated by indirect ELISA. The cutoff points to differentiate positive from negative values were OD values of 0.103 and 0.301 for hamsters and rats, respectively. The OD values followed a different pattern throughout the weeks after infection in each host species (Fig. 1A, B).

The experimentally infected hamsters developed significant antibody responses against E. caproni ES antigens (Fig. 1A). Antibodies were detected in $1(10 \%)$ experimentally infected hamster at 35 DPI. At 42 DPI, $5(50 \%)$ hamsters were positive, whereas at 49 DPI, all the hamsters were positive to ELISA analysis. From this day onward, the antibody levels progressively increased until 119 DPI. At this point until the end of the experiment, the antibody levels remained stable. The mean OD value during the course of the experiment was $0.196 \pm$ 0.024 , whereas the maximum OD value $(0.354 \pm 0.066)$ was observed at 119 DPI. Statistically significant differences between OD values of the sera from infected and control hamsters were detected from 42 DPI until the end of the study $(P<$ 0.02).

Antibody titers against ES antigens of E. caproni in experimentally infected rats over time are shown in Figure 1B. Rats only developed weak responses to E. caproni. Positive levels of antibodies were detected in $4(40 \%)$ of the rats at 49 DPI. At 56 DPI, all the rats were positive to ELISA test. However, $3(30 \%)$ of the rats reverted to negative antibody levels at 77 DPI. From this day onward, the OD values were low in all the infected rats, and mean OD values only were slightly positive at 105 DPI $(0.301 \pm 0.061)$. The mean OD during the complete course of the experiment was $0.281 \pm 0.049$, and the maximum $(0.361 \pm 0.024)$ was observed at 56 DPI. Statistically significant differences between OD values of the sera from infected and control rats only were detected from 56 to 84 DPI $(P<$ $0.05)$.

\section{Detection limits of the capture ELISA}

The detection limits of the capture ELISA to E. caproni ES antigens in sample buffer and fecal extracts from rats were determined previously as 3 and $60 \mathrm{ng} / \mathrm{ml}$, respectively (Toledo, Espert, Muñoz-Antoli et al., 2003). The detection limits in fecal extracts from hamsters and sera from hamsters and rats were determined by measuring serial dilutions of E. caproni ES antigens in fecal extracts and sera from animals naive for helminths. The samples were then tested in triplicate to the capture ELISA. The detection limits were $90 \mathrm{ng} / \mathrm{ml}$ in fecal extracts from hamsters and 30 and $60 \mathrm{ng} / \mathrm{ml}$ in sera from hamsters and rats, respectively. A significant positive correlation was detected between the OD values and the final concentration of antigens 


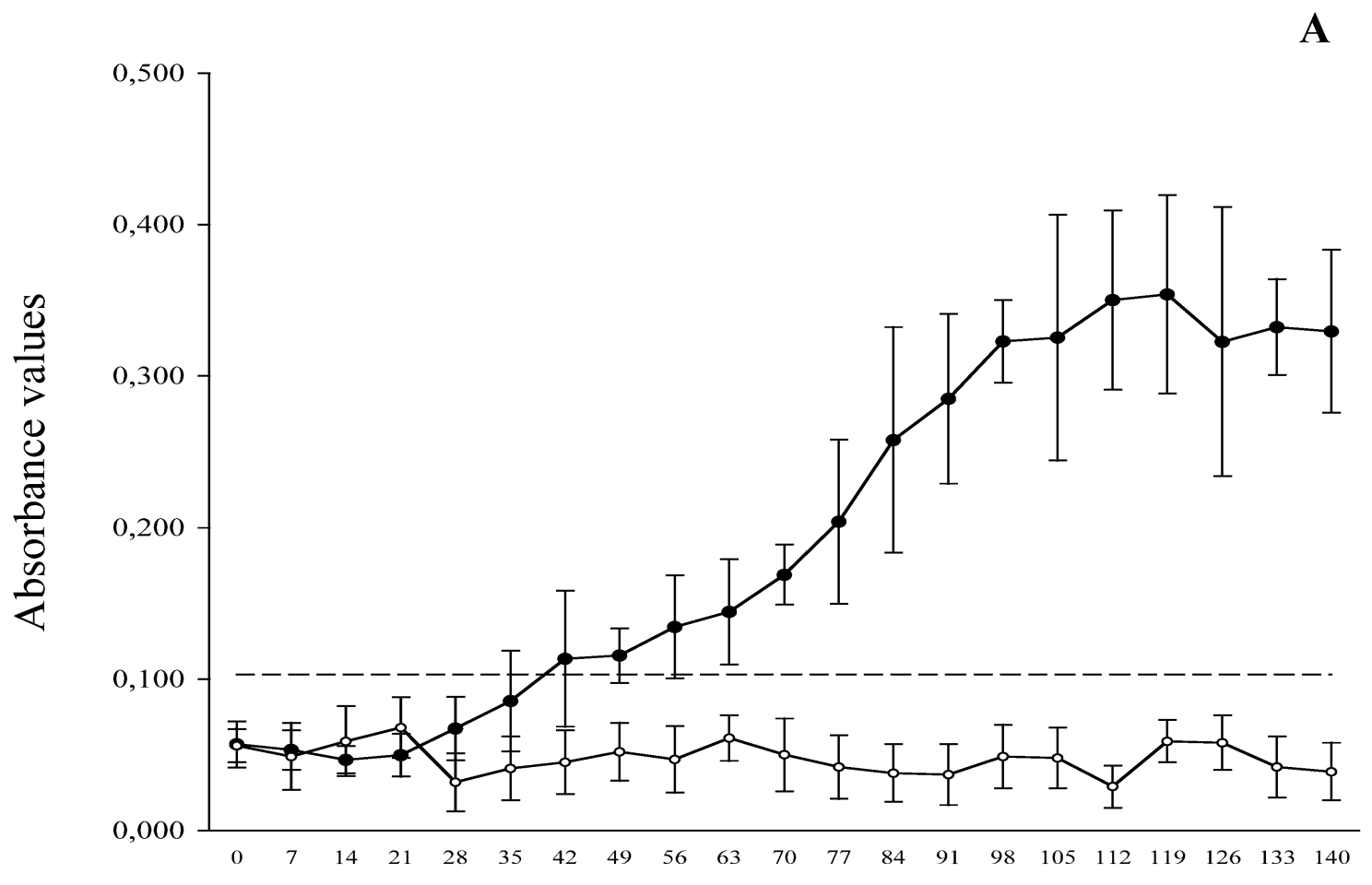

Days post-infection

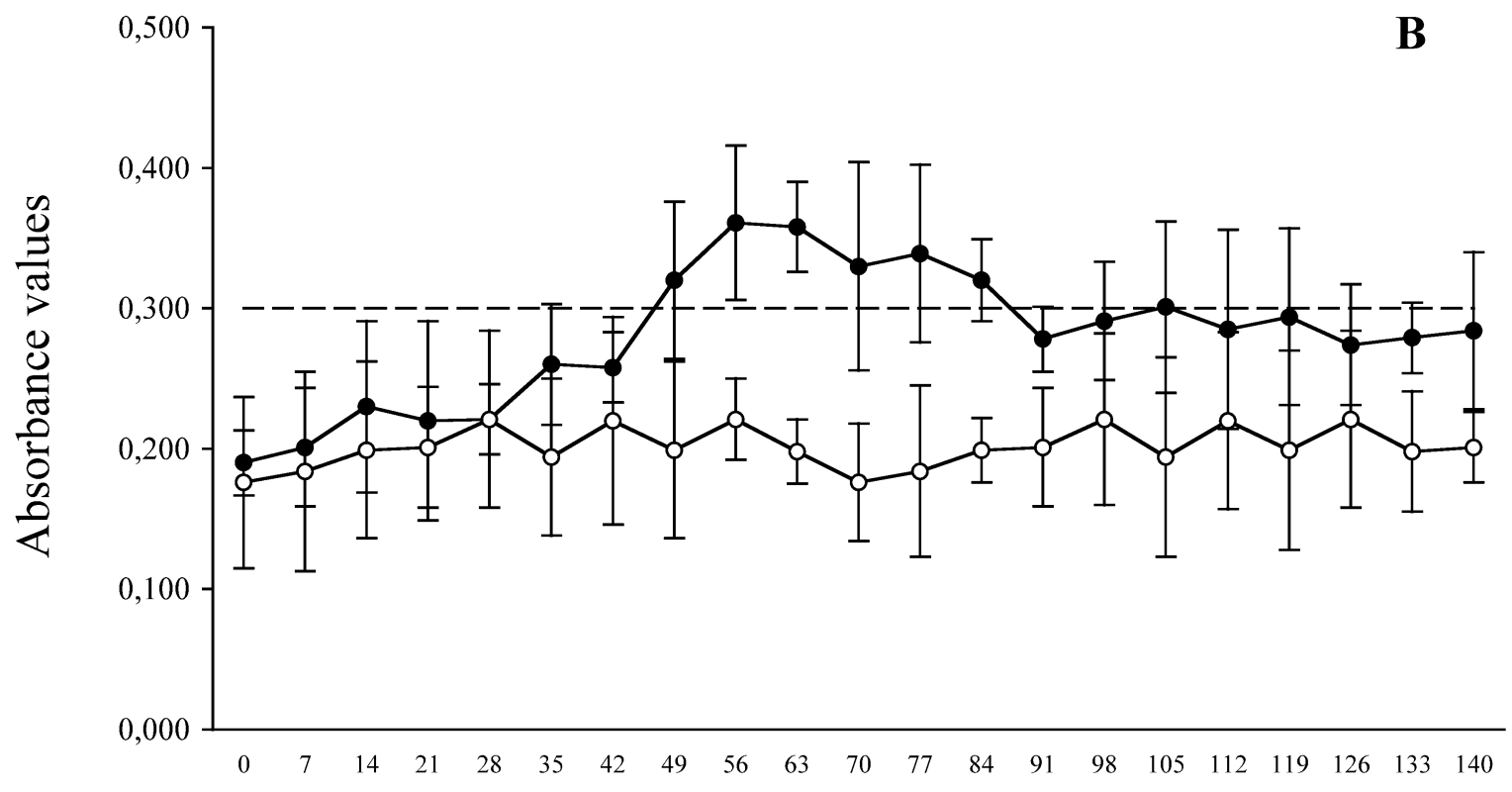

\section{Days post-infection}

FIGURE 1. Detection of antibodies to Echinostoma caproni ES antigens by indirect ELISA in experimentally infected hamsters (A) and rats (B). Mean OD values of control $(\bigcirc)$ and infected $(\bullet)$ animals during the course of the experiment. ( - ) Cutoff point defined as the mean OD value of the controls $+3 \mathrm{SD}$. Vertical bars represent the standard deviation. 


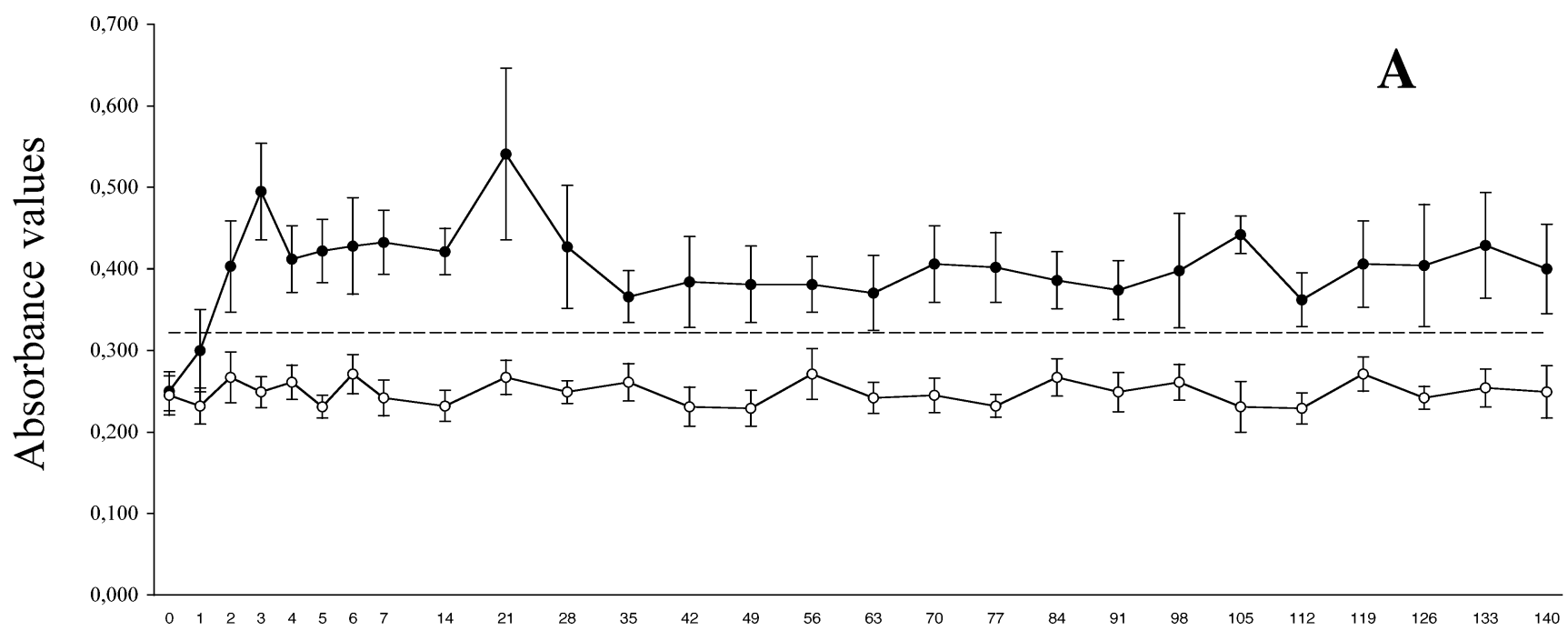

Days post-infection

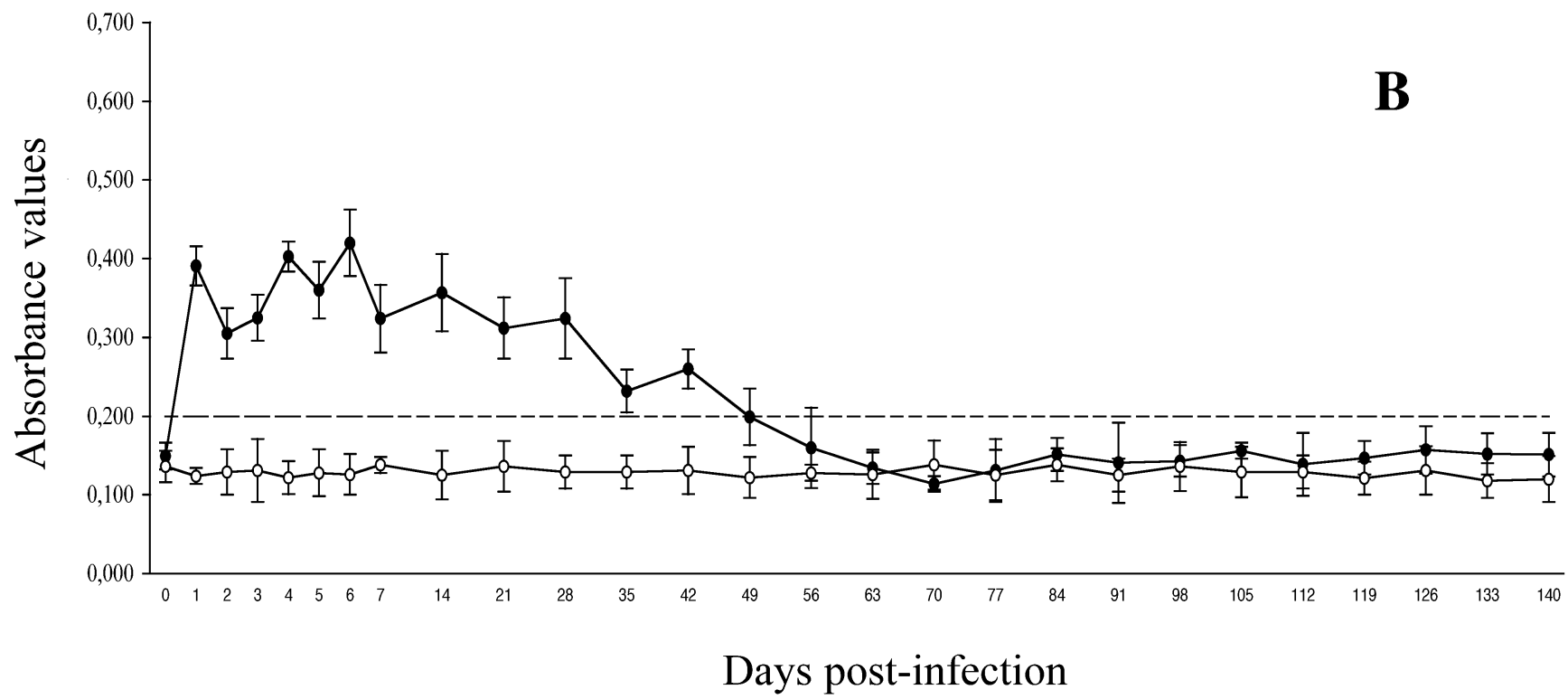

FIGURE 2. Detection of Echinostoma caproni ES antigens in feces of experimentally infected hamsters (A) and rats (B). Mean OD values of control $(\bigcirc)$ and infected $(\bullet)$ animals during the course of the experiment. (-) Cutoff point defined as the mean OD value of the controls $+3 \mathrm{SD}$. Vertical bars represent the standard deviation.

in fecal extracts from hamsters $\left(r_{\mathrm{p}}=0.91 ; \mathrm{n}=20\right)$ and sera from hamsters $\left(r_{\mathrm{p}}=0.88 ; \mathrm{n}=20\right)$ and rats $\left(r_{\mathrm{p}}=0.93 ; \mathrm{n}=\right.$ 20).

\section{Kinetics of coproantigen excretion}

The kinetics of the coproantigen excretion was followed daily during the first week of infection and weekly from 7 to 140 DPI in each host species (Fig. 2A, B). The cutoff values for this technique were calculated as described above and were 0.322 for hamsters and 0.200 for rats.

Four $(40 \%)$ of the infected hamsters were positive from the first DPI, whereas at 2 DPI all of them were positive by capture ELISA analysis and remained positive until the end of the study. The $t$-test showed significant differences $(P<0.05)$ be- tween the OD values from the infected and control hamsters in each sample analyzed from 2 DPI to the end of the experiment. The OD values were more or less constant over time, although the coproantigen excretion appeared to be higher during the first 21 DPI. The maximum OD value $(0.541 \pm 0.044)$ was observed at $21 \mathrm{DPI}$, and the mean OD value during the complete study was $0.425 \pm 0.063$.

The kinetics of $E$. caproni coproantigen excretion in rats is shown in Figure 2B. All the samples analyzed were positive from the first DPI to 49 DPI. The coproantigen excretion rapidly increased to reach a period of high coproantigen excretion during the first DPI. From 21 DPI, the coproantigen levels gradually declined to become negative in $6(60 \%)$ of the rats at 49 DPI and at 56 DPI in the remainder of the rats. From this day onward, all the samples were negative. The coproantigen max- 


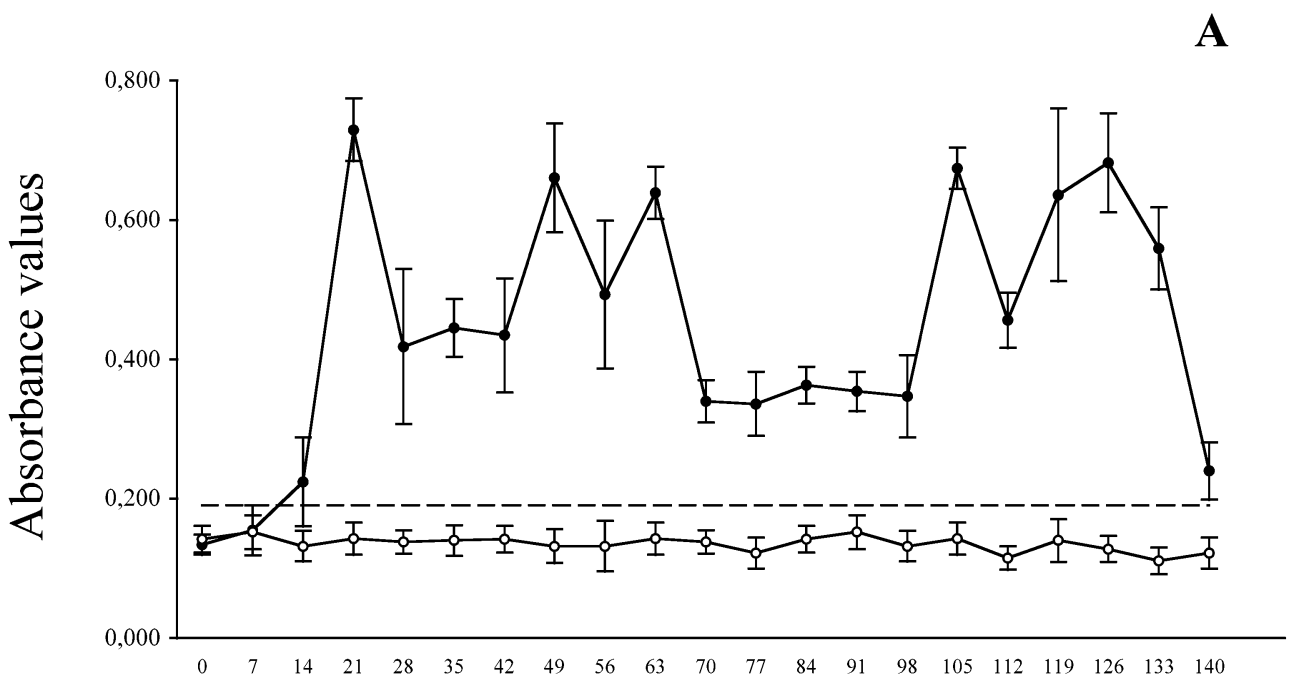

\section{Days post-infection}

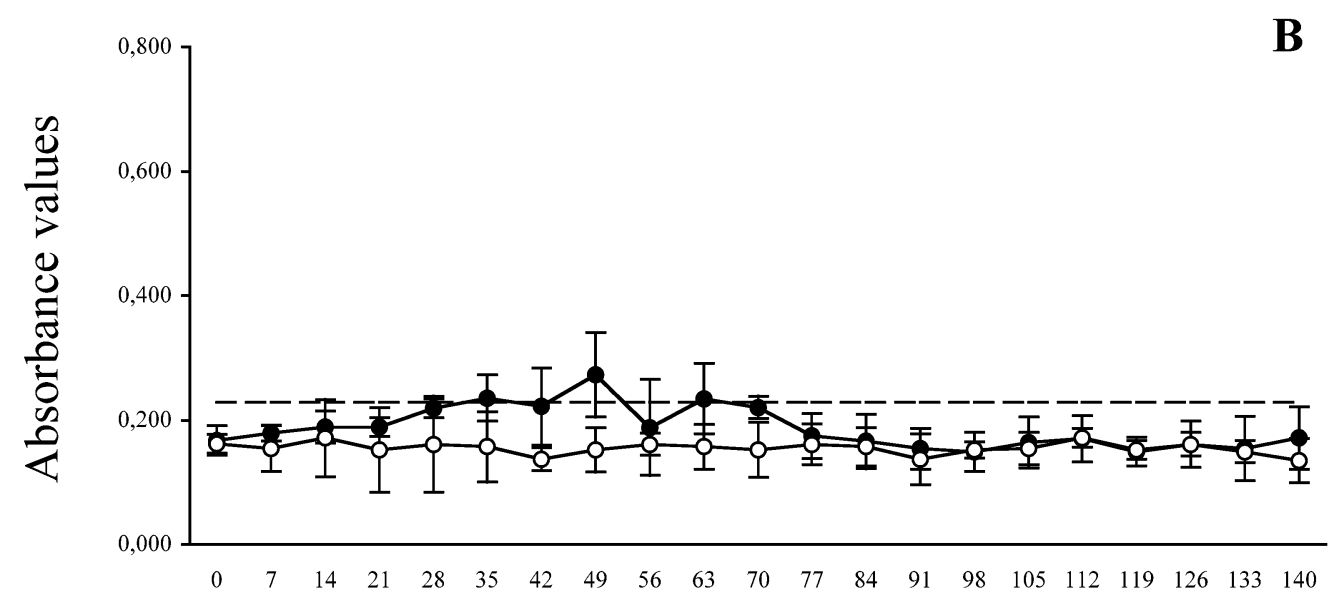

\section{Days post-infection}

FIGURE 3. Detection of Echinostoma caproni ES antigens in sera of experimentally infected hamsters (A) and rats (B). Mean OD values of control $(\bigcirc)$ and infected $(\bullet)$ animals during the course of the experiment. $(-)$ Cutoff point defined as the mean OD value of the controls +3 SD. Vertical bars represent the standard deviation.

imal response $(0.420 \pm 0.042)$ was observed at $6 \mathrm{DPI}$, and the mean OD value during the experiment was $0.238 \pm 0.110$.

\section{Kinetics of seroantigens}

The ELISA for E. caproni seroantigen detection was standardized for this study and used to follow the dynamics of seroantigens in experimentally infected hamsters and rats (Fig. 3A, B).

Echinostoma caproni antigens were detected in serum samples from 14 DPI in 2 (20\%) of the infected hamsters (Fig. 3A). At 21 DPI, all the infected animals were positive for E. caproni-circulating antigen and remained positive until the end of the study. However, the OD values throughout the experiment were variable and 2 periods of high seroantigen detection were detected. The first of these periods occurred from 21 to 56 DPI, and the second was observed from 105 to 126 DPI. Thereafter, the OD values suddenly declined. The mean OD value during the course of the experiment was $0.448 \pm 0.160$, and the maximum OD value was $0.729 \pm 0.045$ observed at 21 DPI. Statistically significant differences between infected and control hamsters were observed for each sample analyzed from 21 DPI until the end of the experiment $(P<0.05)$.

The kinetics of E. caproni seroantigens in rats was significantly different from that observed in hamsters. As shown in Figure $3 \mathrm{~B}$, the seroantigens levels were very low during the experiment, and only positive OD values were obtained at 35 and 49 DPI. The mean OD value during the study was 0.185 \pm 0.032 , and the maximum was detected at 49 DPI $(0.273 \pm$ $0.068)$. Statistically significant differences between infected and control rats were detected at 35 and 49 DPI. 


\section{DISCUSSION}

Previous studies have analyzed the compatibility of E. caproni with different rodent species under experimental conditions. According to these works, hamsters display a high degree of compatibility, whereas rats exhibit a low level of compatibility (Christensen et al., 1988, 1990; Odaibo et al., 1988, 1989; Hansen et al., 1991; Mahler et al., 1995) using the criterion of worm survival. Golden hamsters only develop a limited capacity to expel primary infections resulting in chronic infections. In contrast, E. caproni in rats undergoes a gradual worm rejection, and the infection is lost at 49-70 DPI (Hansen et al., 1991; Toledo, Espert, Muñoz-Antoli et al., 2003). Our study compares the course of the infection in both host species by presenting quantitative data on the kinetics of antibodies and coproantigens. Furthermore, the dynamics of seroantigens is described for the first time in an echinostome infection. The information obtained might be applicable to understand the host-parasite relationships in echinostome infections.

Our study indicates that hamsters and rats display different patterns in the kinetics of antibodies, coproantigens, and serum antigen levels. Echinostoma caproni infections in hamsters were characterized by the production of increasing antibody levels, positive coproantigen levels during the first 140 DPI, and elevated levels of circulating antigens from 14 to 21 DPI. In contrast, rats develop low antibody responses, and the seroantigen levels were low during the study.

The course of the infection is well reflected by the coproantigen levels in each host species. The usefulness of the coproantigen capture ELISA to follow the course of E. caproni infections in rats has been demonstrated previously (Toledo, Espert, Muñoz-Antoli et al., 2003). In this study, we have also used this method to compare the course of the infection in a highly compatible host such as the hamster. Our results confirm that detection of coproantigens is feasible early in the echinostome infection because antigens were detected in feces from 1 to 2 DPI in both host species. Furthermore, the OD values reverted to negative values coinciding with the loss of the infection in rats, whereas in hamsters they remained positive throughout the experiment. In each host species, the coproantigen excretion appears to be higher during the first DPI. This may be related to a period of high activity of the newly excysted metacercariae and juvenile adult worms that may be of importance in parasite establishment. In this sense, Toledo et al. (2004) demonstrated that a number of polypeptides in the ES products are specifically expressed in the juvenile phases of E. caproni.

There is no previous information regarding circulating antigens in echinostome infections, and this constitutes the first report on this topic. Circulating antigens have been detected in other helminth diseases such as neurocysticercosis (Correa et al., 1999; Allan et al., 2003), schistosomiasis (De Jonge et al., 1989), fascioliasis (Langley and Hillyer, 1989; Rodríguez-Pérez and Hillyer, 1995; Doumenigo et al., 2000; Almazan et al., 2001), and trichinellosis (Ivanoska et al., 1989; De la Rosa et al., 2001). The seroantigen detection has often been related to the presence of the worms in close contact with the tissues of the host. For example, circulating antigens in fascioliasis are detected from the first week of infection until the arrival of the flukes in the bile ducts (Doumenigo et al., 2000; Almazan et al., 2001). In contrast, in intestinal helminths with no tissue phase in the definitive host, the detection of circulating antigens is less common. In our study, all the hamsters were positive for E. caproni seroantigens from 14 to 21 DPI until the end of the experiment. Juvenile and adult worms secrete antigens that can cross the intestinal mucosa and reach the circulatory system. In contrast to hamsters, only low levels of serum antigen levels were detected in rats. It is known that passage of antigens through the intestinal mucosa is mediated by local inflammatory responses. Avila et al. (2003) demonstrated that treatment with steroids prevents Taenia solium antigen passage from the intestine to the circulatory system in experimentally infected hamsters. Echinostoma caproni causes progressive intestinal inflammation and an increase in the number of mucosal mast cells in hamsters (Isaacson et al., 1989; Fried et al., 1990; Huffman and Fried, 1990; Fried and Huffman, 1996). Under these conditions, the maintenance of the epithelial barrier is disrupted, resulting in an increase in worm antigen uptake (Kucharzik et al., 2000; Yu and Perdue, 2001). Although the pathological effects of E. caproni in the intestine of rats remain to be studied, the differences in the levels of serum antigen levels with respect to hamsters may reflect weaker local inflammatory responses. The differences in the local inflammatory responses are also supported by the course of E. caproni infection in each host species. In intestinal nematodes, local inflammation, mediated by interferon- $\gamma($ IFN- $\gamma$ ) and other proinflammatory cytokines, inhibits protective immunity resulting in chronic infections (Finkelman et al., 1997; Maizels and Holland, 1998; Maizels and Yazdanbakhsh, 2003). In E. caproni infections, Brunet et al. (2000) reported that the establishment of chronic infections is biased toward a Th1 phenotype and related to elevated levels of IFN- $\gamma$. It is, therefore, likely that differences in local inflammatory responses mediate the establishment of chronic infections in hamsters and the earlier worm rejection in rats.

The antibody production to E. caproni infection in each host species appears to be related to the kinetics of seroantigens. The intestinal absorption of E. caproni antigens induces systemic antibody responses by B-cell stimulation (Graczyk and Fried, 1994). Our results show that E. caproni evokes significant systemic antibody responses in hamsters from 35 to 42 DPI. This is in contrast to the results of Simonsen et al. (1991). They reported that hamsters develop slow and weak humoral immune responses to E. caproni infections, and only low levels of antibodies were detected at 77-91 DPI using crude adult worms as antigen. Probably the greater infective doses and the antigen used in our study may explain, at least in part, the differences observed. Compared with hamsters, rats developed weaker antibody responses. Our results are in agreement with previous studies and only low levels of antibodies were detected from 49 to 84 DPI (Toledo, Espert, Muñoz-Antoli et al., 2003; Toledo et al., 2004). It has been suggested that weak antibody responses to E. caproni infections occur because worm products are not recognized as antigenic by the host or, alternatively, that released parasite products may be immunosuppressive to the host. In contrast, our results show that the distinct systemic antibody responses among host species may be related to the dynamics of worm antigen absorption at the intestinal level.

\section{ACKNOWLEDGMENTS}

This study was supported by Spanish DGICYT project BOS20000570-C02-02 from the Ministerio de Educación, Cultura y Deporte, Ma- 
drid, Spain. This work was carried out when A.E. was a recipient of a predoctoral fellowship from the Ministerio de Educación, Cultura y Deportes, Madrid, Spain. We thank I. Carpena (Valencia) for her assistance. This research complies with the present laws for animal health research in Spain.

\section{LITERATURE CITED}

Allan, J. C., P. P. Wilkins, V. C. Tsang, and P. S. Craig. 2003. Immunodiagnostic tools for taeniasis. Acta Tropica 87: 87-93.

Almazan, C., G. Avila, H. Quiroz, F. Ibarra, and P. OchoA. 2001. Effect of parasite burden on the detection of Fasciola hepatica antigens in sera and feces of experimentally infected sheep. Veterinary Parasitology 97: 101-112.

Avila, G., M. Benitez, L. Aguilar, And A. Flisser. 2003. Kinetics of Taenia solium antibodies and antigens in experimental taeniosis. Parasitology Research 89: 284-289.

Brunet, L. R., J. D. W. Dunne, And B. Fried. 2000. Immune responses during the acute stages of infection with the intestinal trematode Echinostoma caproni. Parasitology 120: 565-571.

Christensen, N. Ø., A. В. Odaibo, and P. Simonsen. 1988. Echinos toma population regulation in experimental rodent definitive hosts Parasitology Research 75: 83-87.

, P. Simonsen, A. B. Odaibo, And H. Mahler. 1990. Establishment, survival and fecundity in Echinostoma caproni (Trematoda) infections in hamsters and jirds. Journal of the Helminthological Society of Washington 57: 104-107.

Correa, D., E. Sarti, R. Tapia-Romero, R. Rico, I. Alcantara-Aguiano, A. Salgado, L. Valdez, and A. Flisser. 1999. Antigens and antibodies in sera from human cases of epilepsy or taeniasis from an area of Mexico where Taenia solium is endemic. Journal of Tropical Medicine and Parasitology 93: 69-74.

De Jonge, N., Y. E. Fillie, G. W. Hilberath, F. W. Krjiger, C. LenGeler, D. H. De Savigny, N. G. Van Vliet, and A. M. Deeler. 1989. Presence of the schistosome circulating anodic antigen (CAA) in urine of patients with Schistosoma mansoni or S. haematobium infections. American Journal of Tropical Medicine and Hygiene 41: 563-569.

De la Rosa, J. L., E. Moran-Tlatelpa, Y. Medina, A. Gomez-Priego, AND D. CoRrEA. 2001. Detection of circulating and fecal Trichinella spiralis antigens during experimental infection using monoclonal antibodies against the new born larvae. Parasite 8: S123S125.

Doumenigo, B. E., A. M. Espino, C. M. Finley, and M. Mezo. 2000 Kinetics of antibody-based antigen detection in serum and feces of sheep experimentally infected with Fasciola hepatica. Veterinary Parasitology 89: 153-161.

Finkelman, F. D., T. Shea-Donohue, J. Goldhill, C. A. Sullivan, S. C. Morris, K. B. Madden, W. C. Gause, and J. F. Urban Jr. 1997. Cytokine regulation of host defense against parasitic gastrointestinal nematodes: Lessons from studies with rodent models. Annual Reviews in Immunology 15: 505-533.

Fried, B., AND J. E. HufFMAn. 1996. The biology of the intestinal trematode Echinostoma caproni. Advances in Parasitology 38: 311368.

- $\longrightarrow$ AND P. M. WEISS. 1990. Single and multiple worm infections of Echinostoma caproni (Trematoda) in the golden hamster. Journal of Helminthology 64: 75-78.

GRACZYK, T. K., AND B. FRIED. 1994. ELISA method for detecting antiEchinostoma caproni (Trematoda) antibodies in experimentally infected ICR mice. Journal of Parasitology 80: 544-549.

Hansen, K., J. W. Nielsen, O. Hindsbo, and N. Ø. Christensen. 1991. Echinostoma caproni in rats: Worm population dynamics and host blood eosinophilia during primary 6,25 and 50 metacercarial in- fections, and resistance to secondary and superimposed infections. Parasitology Research 77: 686-690.

Hosier, D. W., AND B. FRIED. 1991. Infectivity, growth and distribution of Echinostoma revolutum in Swiss Webster and mice. Proceedings of the Helminthological Society of Washington 53: 173-176.

HufFmAn, J. E., AND B. FrIED. 1990. Echinostoma and echinostomiasis. Advances in Parasitology 29: 215-269.

IsAacson, A., J. E. Huffman, AND B. FrIED. 1989. Infectivity, growth, development and pathology Echinostoma caproni (Trematoda) in the golden hamster. International Journal for Parasitology 19: 943944.

Ivanoska, D., K. Cuperiovic, H. R. Gamble, and K. D. Murrell. 1989. Comparative efficacy of antigen and antibody detection tests for human trichinellosis. Journal of Parasitology 75: 38-41.

Kucharzik, T., N. Lugering, K. Rautenberg, A. Lugering, N. A. Schmidt, R. Stoll, And W. DomschKe. 2000. Role of $\mathrm{M}$ cells in intestinal barrier function. Annales of the New York Academy of Sciences 915: 171-183.

LANGley, R. J., AND G. V. Hillyer. 1989. Detection of circulating parasite antigen in murine fascioliasis by two-site enzyme-linked immunosorbent assays. American Journal of Tropical Medicine and Hygiene 41: 472-478.

Mahler, H., N. Ø. Christensen, And O. Hindsbo. 1995. Studies on the reproductive capacity of Echinostoma caproni (Trematoda) in hamsters and jirds. International Journal for Parasitology 25: 705-710.

Maizels, R. M., AND M. J. Holland. 1998. Pathways for expelling intestinal helminths. Current Biology 8: R711-R714.

, AND M. YAZDANBAKHSH. 2003. Immune regulation by helminth parasites: Cellular and molecular mechanisms. Nature Reviews Immunology 3: 733-744.

Odaibo, A. B., N. Ø. Christensen, And F. M. A. Ukoli. 1988. Establishment survival and fecundity in Echinostoma caproni (Trematoda) infections in NMRI mice. Proceedings of the Helminthological Society of Washington 55: 265-269.

- $\longrightarrow$ AND $\longrightarrow$ 1989. Further studies on the population regulation in Echinostoma caproni infections in NMRI mice. Proceedings of the Helminthological Society of Washington 56: 192198.

Rodríguez-PÉrez, J., AND G. V. Hillyer. 1995. Detection of excretorysecretory circulating antigens in sheep infected with Fasciola hepatica and with Schistosoma mansoni and $F$. hepatica. Veterinary Parasitology 56: 57-66.

Simonsen, P. E., B. B. Estambale, And M. Agger. 1991. Antibodies in the serum of golden hamsters experimentally infected with the intestinal trematode Echinostoma caproni. Journal of Helminthology 65: 239-247.

Toledo, R., A. Espert, I. Carpena, C. Muñoz-Antoli, and J. G. EsTEBAN. 2003. An experimental study of the reproductive success of Echinostoma friedi (Trematoda: Echinostomatidae) in the golden hamster. Parasitology 126: 433-441.

B. FRIED, AND J. G. ESTEBAN. 2004. Immunological characterization of somatic and excretory/secretory antigens of Echinostoma caproni (Trematoda: Echinostomatidae) in experimentally infected rats. Comparative Parasitology 71: 4248 .

C. Muñoz-Antoli, A. Marcilla, B. Fried, AND J. G. Esteban. 2003. Development of an antibody-based capture enzyme-linked immunosorbent assay for detecting Echinostoma caproni (Trematoda) in experimentally infected rats: Kinetics of coproantigen excretion. Journal of Parasitology 89: 1227-1231.

Van Kerckhoven, I., W. Vansteenkiste, M. Claes, S. Geerts, and J. BRANDT. 1998. Improved detection of circulating antigens in cattle infected with Taenia saginata metacestodes. Veterinary Parasitology 76: 269-274.

Yu, L. C. H., AND M. H. PuRdue. 2001. Role of mast cells in intestinal mucosa function: Studies in models of hypersensitivity and stress. Immunological Reviews 179: 61-73. 